\title{
SIMULASI NUMERIK PENGARUH ALIRAN UDARA TERHADAP KARAKTERISTIK SEMPROTAN BIOETANOL DALAM INTAKE MANIFOLD
}

\author{
Budi Suharto \\ Jurusan Teknik Konversi Energi - Politeknik Negeri Bandung \\ E-mail:budi.suharto@yahoo.co.id
}

\begin{abstract}
Abstrak
Penelitian ini dilakukan secara numerik menggunakan software FLUENT dengan tujuan untuk mempelajari proses pembentukan droplet lebih rinci. Secara teoritis, pembentukan droplet dalam semprotan diawali dengan pembentukan lapisan tipis kemudian ligament serta droplet. Droplet tersebut akan mengalami breakup saat bergesekan dengan udara. Proses breakup ini akan mengalami perubahan saat semprotan tersebut berada pada sebuah intake manifold karena aliran udara berada pada posisi tegak lurus. Ketika sudut katup $30^{\circ}, 60^{\circ}$ atau $90^{\circ}$ akan terjadi perubahan tekanan dan kecepatan pada area sekitar tepi katup dan dinding intake manifold. Area dengan celah kecil akan memiliki kecepatan tertinggi yaitu $307 \mathrm{~m} / \mathrm{s}$ pada bukaan katup $30^{\circ}, 133 \mathrm{~m} / \mathrm{s}$ pada bukaan katup $60^{\circ}$, sedangkan bukaan katup lebar $90^{\circ}$ hanya menimbulkan kecepatan $64,6 \mathrm{~m} / \mathrm{s}$. Hal ini akan berpengaruh pada proses pencampuran bahan bakar dan udara sehingga tidak sesuai komposisimya secara stoikhiometri dimana dalam pembakaran sempurna, perbandingan udara dan ethanol 9,1:1. Oleh karena itu pada penelitian ini, masalah tersebut akan diatasi menggunakan metode simulasi untuk mempelajari pengaruh wake pada semprotan bahan bakar bensin, E85 dan E100.
\end{abstract}

Keywords : droplet, bioethanol spray

\section{PENDAHULUAN}

Bioethanol adalah alkohol liquid yang memiliki kandungan unsur oksigen, hidrogen dan karbon. Di beberapa negara, bahan bakar ini diproduksi dari fermentasi gula yang diperoleh dari jagung atau gandum. Pengembangan bahan bakar alternatif diharapkan dapat mengurangi ketergantungan terhadap bahan bakar fosil yang persediaannya semakin menipis dan hasil pembakarannya memiliki kadar emisi yang tinggi. Bioethanol merupakan bahan bakar alternatif yang dapat digunakan pada motor bensin karena memiliki nilai oktan cukup tinggi dan menghasilkan emisi lebih rendah daripada bensin. Bioethanol sebagai bahan bakar dapat digunakan melalui tiga cara, yaitu dicampur langsung dengan bensin, diolah menjadi ethyl tertiary butyl ether (ETBE), atau etanol murni sebagai pengganti bensin. Penggunaan bioetanol murni pada motor bakar dapat dilakukan pada engine yang dilengkapi sistem injeksi bahan bakar. Sistem tersebut diperlukan agar proses atomisasi etanol berlangsung sempurna dan menciptakan droplet yang dapat bereaksi dengan udara.

Bahan bakar campuran bensin dan etanol terbukti dapat memperbaiki masalah saat penyalaan awal selama musim dingin dan telah dipasarkan di beberapa negara antara lain Amerika Serikat menggunakan E70 sedangkan Swedia menggunakan E85, (Davis, 2002). Dewasa ini beberapa produsen otomotif bahkan telah memasarkan kendaraan berbahan bakar etanol murni (E100) walaupun jumlahnya sedikit. Tantangan pengembangan kendaraan berbahan bakar bioetanol murni terletak pada sistem bahan bakarnya karena bioetanol memerlukan sistem atomisasi yang baik.

Computational Fluid Dynamic merupakan alat bantu yang digunakan untuk menyelesaikan persamaan matematis yang berkaitan dengan aliran fluida. Dengan CFD, pemodelan dan visualisasi semprotan pada submodel dapat dipelajari lebih rinci dan pemilihan parameter 
tentang suatu kasus fluida umumnya dikaitkan dengan hasil dari eksperimen sebelumnya. Dengan menggunakan pemodelan yang tepat maka hasil post processing dari perangkat lunak ini akan memiliki trend yang sama dengan eksperimen

Menurut Bechtold (1997) penerapan etanol sebagai bahan bakar dapat menggunakan tiga cara, yaitu langsung dicampur bensin dengan komposisi etanol sekitar $10 \%$ (biasanya disebut gasohol), diolah menjadi ethyl tertiary butyl ether (ETBE), (Menezes, 2008) dan etanol murni sebagai pengganti bensin dengan komposisi etanol sebanyak $85 \%$ (E85). Ketiga komposisi tersebut telah diproduksi dan dipasarkan di beberapa negara, (Paasi dan Hira, 2009).

Penggunaan bioethanol murni pada engine dengan sistem bahan bakar karburator tidak dapat dilakukan karena proses atomisasi tidak berlangsung sempurna. Hal ini dapat diatasi dengan mencampur bioethanol dengan bahan bakar. Beberapa penelitian telah membuktikan bahwa penambahan etanol dalam bahan bakar dapat meningkatkan kinerja engine, mengurangi kadar emisi gas buang dan menambah nilai oktan. Yucesu dkk (2006) melakukan eksperimen menggunakan mesin Hydra silinder tunggal dengan perbandingan kompresi 8:1 hingga 13:1, sistem bahan bakar injeksi dan menggunakan putaran mesin 2000, 3500 dan $5000 \mathrm{rpm}$. Bahan bakar yang digunakan adalah bensin (E0) dan campuran bensin dengan etanol E10, E20, E30, E40 dan E60. Eksperimen ini dapat menjelaskan bahwa peningkatan perbandingan kompresi akan menghasilkan torsi besar dan hemat bahan bakar. Penggunaan perbandingan kompresi tersebut harus disesuaikan dengan karakteristik bahan bakar karena E0 dan campuran low etanol lebih mudah mengalami detonasi daripada high etanol. Pada perbandingan kompresi 13 (tinggi), bensin (E0) akan mengalami detonasi pada $10^{\circ}$ BTDC sedangkan E10 menyebabkan detonasi tertunda menjadi $15^{\circ}$ sebelum TMA dan E40 menunda detonasi menjadi $17^{\circ}$ sebelum TMA.

Proses atomisasi semprotan full cone pada sac nozzle dijelaskan Baumgarten (2006). Ketika meninggalkan nozzle, jet mulai break up membentuk semprotan yang bersudut. Primary break up adalah break up pada awal semprotan dan menghasilkan ligamen serta droplet yang membentuk dense spray sekitar nozzle. Pada injeksi tekanan tinggi, kavitasi dan turbulen dalam lubang injeksi adalah penyebab awal mekanisme break up. Perbedaan kecepatan relatif antara droplet dan gas akan menimbulkan gaya aerodinamik yang dapat memperlambat laju droplet dan menyebabkan droplet pecah menjadi lebih kecil, peristiwa ini dinamakan secondary breakup. Droplet sekitar spray tip memiliki gaya drag paling besar dan kecepatannya lebih lambat daripada droplet dalam area wake sedangkan droplet dengan energi kinetik rendah didorong ke arah radial dan membentuk semprotan bagian terluar hingga membentuk sudut (spray cone angle). Fasa liquid banyak terdapat di sekitar sumbu semprotan daripada di bagian luar semprotan, kecepatan droplet tertinggi berada pada daerah sumbu dan berkurang ke arah radial akibat interaksi droplet dengan gas. Dense spray memiliki peluang sangat besar untuk collision yang dapat menyebabkan kecepatan dan ukuran droplet berubah menjadi lebih kecil atau bergabung menjadi besar yang biasa disebut coalescence.

Menurut Heywood (1988), kondisi injeksi seperti tekanan injeksi, area orifice dan injection rate berubah saat injeksi sehingga distribusi ukuran droplet dalam semprotan akan berubah selama periode injeksi. Hal ini menunjukkan proses atomisasi akan berbeda sesuai spray cone dan spray edge, dan lintasan individual droplet tergantung dari ukuran, kecepatan awal dan posisi dalam semprotan. Proses atomisasi tersebut menjelaskan penyebab distribusi ukuran droplet selalu berbeda sesuai posisinya dalam semprotan.

Liimata dkk (1971) telah membuat visualisasi aliran di sekitar butterfly valve dan menjelaskan bahwa pada bukaan katup $20^{\circ}$ hingga $45^{\circ}$ terdapat aliran jet dua dimensi pada kedua sisi butterfly valve. Aliran mengalami percepatan setelah keluar dari venturi dan separasi terjadi didepan bagian katup tengah. Akibat separasi 
tersebut aliran terpisah dan mengarah pada kedua tepi katup. Pada bagian belakang katup terjadi wake yang memiliki dua vortex dengan arah berlawanan. Jet yang terjadi pada tepi katup mengalir sedemikian rupa sehingga sangat kecil kemungkinan kedua aliran tersebut dapat bergabung di belakang butterfly valve.

Melalui eksperimen yang dilakukan oleh Park (1989) diketahui bahwa distribusi campuran bahan bakar pada karburator dipengaruhi oleh sudut dan bentuk butterfly valve. Pada eksperimen ini lapisan bahan bakar akan terbentuk dalam intake manifold pada arah downstream setelah venturi. Eksperimen dilaksanakan menggunakan model intake manifold dengan venturi terletak horizontal dan metanol sebagai bahan bakar. Lapisan tipis (liquid film) diukur sepanjang $400 \mathrm{~mm}$ dan ketebalannya diukur menggunakan sensor elektronik setiap $50 \mathrm{~mm}$. Penelitian ini menjelaskan bahwa lapisan ini terbentuk akibat gaya gravitasi dan tidak dipengaruhi oleh bukaan katup melainkan kecepatan udara dalam intake manifold, udara kecepatan tinggi menyebabkan ketebalan lapisan semakin berkurang.. Untuk meningkatkan laju atomisasi diciptakan the Eco-Ring (venturi yang dilengkapi empat lubang berdiameter $3 \mathrm{~mm}$ sekitar dindingnya) yang ditempatkan setelah karburator dengan tujuan membuat lapisan bahan bakar di dinding teratomisasi sehingga laju atomisasi lebih baik dan menghasilkan distribusi campuran yang homogen.

Pada sistem bahan bakar menggunakan karburator, wake tersebut mempengaruhi proses pencampuran bahan bakar dengan udara serta menimbulkan lapisan tipis bioetanol pada dinding sehingga kinerja engine menurun. Kerugian ini dapat dikurangi dengan menggunakan sistem injeksi bahan bakar dan menempatkan injektor setelah butterfly valve. Sistem injeksi bahan bakar yang digunakan pada kendaraan modern adalah multi-port injection dan throttle body injection, Crouse dan Anglin (1993). Multi-port injection adalah sistem bahan bakar yang dilengkapi injektor untuk setiap silinder, sedangkan throttle body injection atau single point injection adalah sistem bahan bakar yang -menggunakan sebuah injektor untuk sebuah intake manifold.

Eksperimen dilakukan oleh Furuyama dan Ohgane (1987) serta Moss (1980) yang membuktikan bahwa pulsa aliran dalam intake manifold timbul saat katup terbuka penuh dengan kecepatan udara rendah dan katup terbuka penuh dengan kecepatan udara tinggi. Menurut Behnia (2001), Milton (2001) dan Kale (2005), kecepatan dan pola aliran udara yang masuk dalam intake manifold akan mengendalikan massa bahan bakar yang diatomisasikan dan dapat membuat lapisan tipis bahan bakar pada dinding.

Milton dkk (1994) melakukan penelitian numerik menggunakan software FLOW3D untuk mempelajari aliran bahan bakar di dalam intake manifold posisi horizontal berdiameter $0,03 \mathrm{~m}$ dan kecepatan udara 5 hingga $30 \mathrm{~m} / \mathrm{s}$ serta pasokan bahan bakar menggunakan sistem injeksi. Pada penelitian pertama, injektor bahan bakar diletakkan sebelum butterfly valve sedangkan pada penelitian kedua, injektor diletakkan setelah butterfly valve.

Hasil penelitian pertama menunjukkan bahwa saat butterfly valve ditutup terjadi perbedaan tekanan sangat tinggi yang menyebabkan daerah wake pada downstream bertambah luas. Penutupan aliran manifold tersebut menyebabkan bahan bakar menempel pada dinding katup dan berkurang saat aliran terbuka kembali. Saat aliran tertutup, bahan bakar menempel pada katup bagian depan hingga $75 \%$ dan membuat lapisan tipis pada sisi depan karena sisi tersebut berada tepat setelah aliran jet dari injektor sebaliknya di sekitar dinding manifold bagian bawah lapisan tipis bahan bakar mencapai maksimum hingga $20 \%$ saat aliran terbuka penuh. Lapisan tersebut semakin tipis saat katup mulai menutup karena terjadi aliran berkecepatan tinggi pada daerah antara katup dan dinding bawah. Pada penelitian dengan bukaan katup $60^{\circ}$ dan kecepatan udara meningkat hingga $30 \mathrm{~m} / \mathrm{s}$ memberikan pengaruh lebih baik karena udara kecepatan tinggi akan membawa bahan bakar melalui intake manifold dan bahan bakar yang menempel pada dinding katup dan saluran sangat sedikit. 
Behnia dkk (2001) melakukan eksperimen pada sebuah model intake manifold menggunakan campuran kerosene dan menunjukkan bahwa pola aliran pada arah downstream di belakang butterfly valve memiliki vortex dengan arah aliran saling berlawanan. Hal ini menunjukkan wake di sekitar butterfly valve akan mengendalikan lapisan tipis bahan bakar dalam saluran manifold.

Melalui penelitian pola aliran menggunakan particle image velocimetry, Krishna dkk (2008) menjelaskan bahwa aliran campuran bahan bakar dan udara dalam intake manifold memiliki energi kinetik turbulen (TKE) yang dapat mempengaruhi kinerja motor bakar. Eksperimen ini bertujuan untuk mempelajari pengaruh sudut intake manifold dengan beragam putaran mesin terhadap TKE. Hasil eksperimen menunjukkan bahwa TKE terbesar terbentuk saat menggunakan intake manifold bersudut $60^{\circ}$.

Parameter injeksi akan berpengaruh terhadap sebuah pola semprotan bahan bakar. Faktor lainnya yang berpengaruh adalah viskositas, densitas dan tegangan permukaan. Penelitian numerik tentang hal ini telah dilakukan Wulung (2009) menggunakan dua jenis biodiesel terbuat dari jarak dan minyak goreng bekas. Hasil penelitian menunjukkan bahwa bahan bakar dengan viskositas rendah akan mengalami break up secara cepat dan tumbukan droplet dengan dinding akan mengalami regim spread

\section{METODOLOGI}

Dalam penelitian ini akan dipelajari karakteristik semprotan bioetanol di bagian intake manifold pada motor bensin. Ukuran pemodelan intake manifold ini dibuat berdasarkan ukuran intake manifold di Laboratorium Motor Bakar Jurusan Teknik Konversi Energi. Penelitian ini dlakukan dengan menggunakan software Fluent 6.3. Fluent adalah salah satu jenis program CFD yang menggunakan metode volume hingga.

Pada penelitian pertama, injektor diletakkan sebelum butterfly valve kemudian dilakukan simulasi sedangkan pada penelitian kedua injektor diletakkan setelah butterfly valve.
Kecepatan udara masuk intake manifold diasumsikan uniform dan dipilih sesuai dengan perhitungan stokiometri untuk memperoleh pembakaran sempurna.

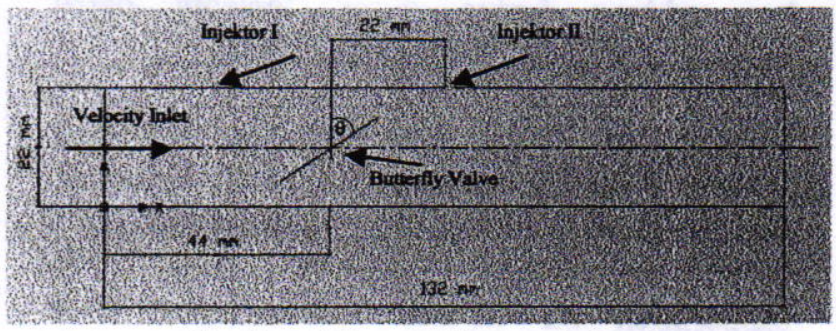

Gambar 1 Geometri ruang bakar tipe Mexican-Hat

Persamaan reaksi untuk pembakaran sempurna etanol dalam ruang bakar adalah,

Dimana,

$$
\mathrm{C}_{2} \mathrm{H}_{3} \mathrm{OH}+3 \mathrm{O}_{2} \rightarrow 2 \mathrm{CO}_{2}+\mathrm{H}_{2} \mathrm{O}
$$

Massa relatif atom-atom penyusun bioetanol yaitu :

Carbon, $\mathrm{C}: 12$

Hidrogen, $\mathrm{H}: 1$

Oxygen, 0: 16

Sehingga, massa molekul relatif etanol adalah (2 $\mathrm{x} 12)+(1 \times 5)+16+1=46$. Dan massa molekul relatif oksigen $3(2 \times 16)=96$.

Dalam pembakaran sempurna, perbandingan oksigen dan etanol adalah $96: 46=2,1$, dengan kata lain untuk membakar $1 \mathrm{~kg}$ bioetanol dalam ruang bakar diperlukan $2,1 \mathrm{~kg}$ udara. Kandungan oksigen dalam udara sekitar $23 \%$ maka untuk memperoleh $1 \mathrm{~kg}$ oksigen diperlukan 4,35 $\mathrm{kg}$ udara. Massa oksigen diperlukan dalam penelitian $(2,1 \mathrm{~kg})$ dapat dipenuhi jika 2,1 x 4,35 $=9,1$ udara masuk dalam intake manifold. Penelitian ini menggunakan intake manifod berdiameter $22 \mathrm{~mm}$ sepanjang $132 \mathrm{~mm}$. Oleh karena itu untuk menciptakan pembakaran ideal $(\emptyset=1)$ diperlukan udara kecepatan $60 \mathrm{~m} / \mathrm{s}$ yang mengalir dalam intake manifold. Ganesan (2002), mendefinisikan pengaruh fuel-air ratio sebagai,

$$
\phi=\frac{\text { Actual Fuel }- \text { AirRatio }}{\text { Stoichiometri Fuel }- \text { AirRatio }}
$$


Dimana, $\varnothing=1$ adalah komposisi campuran bahan bakar-udara yang ideal, sedangkan $\emptyset<1$ adalah campuran miskin (lean) dan $\emptyset>1$ merupakan campuran kaya (rich)

Tabel 1 Hasil Perhitungan Kecepatan dan Fuel-Air Ratio dalam Intake Manifold

\begin{tabular}{|c|c|c|c|}
\hline No & Kecepatan udara $(\mathrm{m} / \mathrm{s})$ & $\emptyset$ & Jenis campuran \\
\hline 1 & 70 & 0,9 & Lean \\
\hline 2 & 60 & 1 & Ideal \\
\hline 3 & 50 & 1,2 & Rich \\
\hline
\end{tabular}

Bahan bakar yang digunakan dalam penelitian numerik ini adalah bensin dan campuran bensinbioethanol E85, E100. Tabel 2 menunjukkan hasil pengujian ketiga bahan bakar tersebut. Bensin memiliki nilai kalor tertinggi dengan nilai oktan rendah sedangkan bioetanol E100 memiliki nilai kalor paling rendah.

Tabel 2 Spesifikasi Bahan Bakar

\begin{tabular}{|c|c|c|c|c|}
\hline No & Bahan Bakar & Bensin & E85 & E100 \\
\hline 1 & Densitas (kg/L) & 0,79 & 0,79 & 0,79 \\
\hline 2 & Viskositas (cP) & 0,44 & 1,08 & 1,19 \\
\hline 3 & MON & 88 & 89 & 89,7 \\
\hline 4 & LHV (kJ/L) & 33000 & 22900 & 21000 \\
\hline
\end{tabular}

\section{HASIL DAN PEMBAHASAN}

Hasil penelitian ini menunjukan bahwa semprotan bioetanol akan memiliki spray cone angle dan panjang penetrasi bertambah seiring dengan bertambahnya waktu. Hal ini disebabkan karena droplet mengalami waktu yang lebih lama untuk bergesekan dengan udara. Proses ini mudah dilakukan fluida cair jika memiliki kecepatan relatif yang tinggi antara liquid yang akan diatomisasi dengan udara atau gas yang ada disekitarnya. Droplet pada tepi semprotan lebih cepat break up atau pecah daripada di tengah semprotan., karena droplet pada bagian tengah memiliki energi kinetik lebih besar dibandingkan tepi. Pecahnya droplet menjadi bagian yang lebih kecil adalah akibat gaya geser (dari gaya aerodinamis) pada bagian terlemah dari droplet yang terlebih dahulu berdeformasi.

Tahap pertama pembentukan droplet bioetanol diawali dengan kavitasi di dalam injektor lalu saat melintasi nozzle tip terbentuklah sheet, ligament lalu droplet. Proses tersebut dikenal dengan nama primary breakup. Tahap selanjutnya adalah secondary breakup dimana droplet pecah menjadi berukuran kecil akibat bergesekan dengan udara. Dalam kondisi aktual, droplet tersebut bertabrakan dengan droplet lainnya sehingga breakup terjadi kembali (collision) dan pada beberapa kasus droplet bergabung membentuk ukuran lebih besar (coalescence). Hasil penelitian numerik ini menunjukkan baik semprotan bensin, E85 maupun E100 hanya mengalami collision yang terukur pada post processing dengan diameter berkisar antara 18,8-134 $\mu \mathrm{m}$.

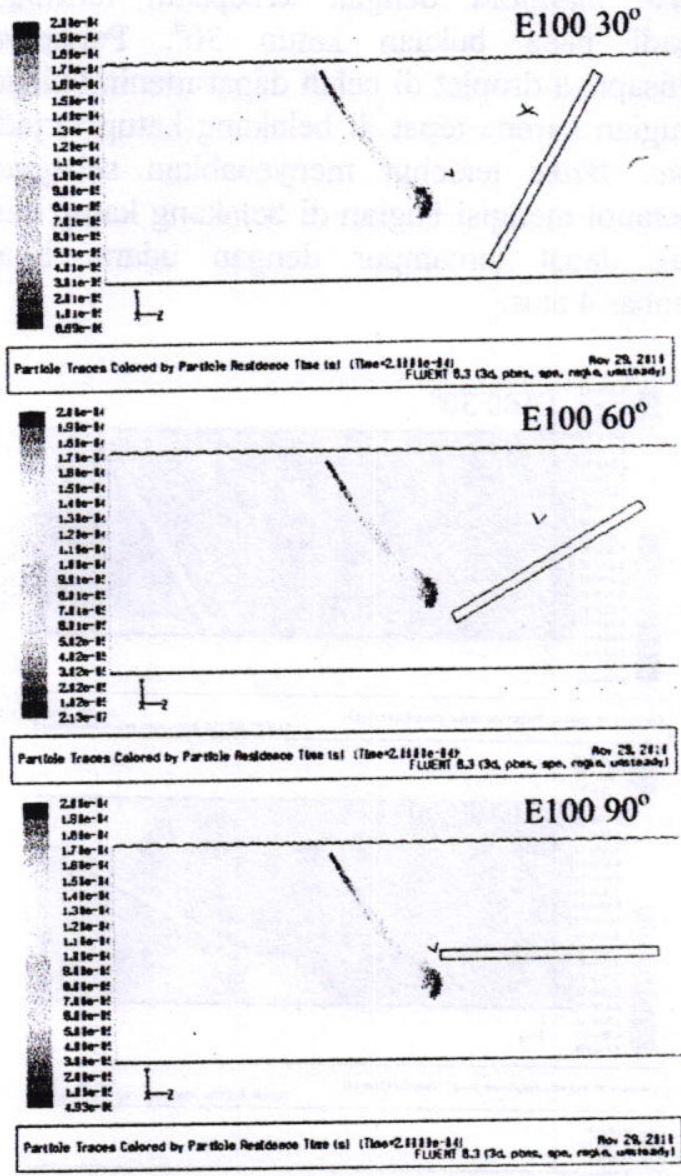

Gambar 2 Pengaruh sudut butterfly pada distribusi droplet

Ketika sudut katup $30^{\circ}, 60^{\circ}$ atau $90^{\circ}$ akan terjadi perubahan tekanan dan kecepatan pada area sekitar tepi katup dan dinding intake manifold. Area dengan celah kecil akan memiliki kecepatan tertinggi yaitu $307 \mathrm{~m} / \mathrm{s}$ pada bukaan katup $30^{\circ}, 133 \mathrm{~m} / \mathrm{s}$ pada bukaan katup $60^{\circ}$ 
sedangkan bukaan katup lebar $90^{\circ}$ hanya menimbulkan kecepatan $64,6 \mathrm{~m} / \mathrm{s}$.

Gambar 2 merupakan hasil simulasi semprotan bahan bakar E100 pada beberapa posisi bukaan katup. Dari gambar tersebut diketahui bahwa celah yang kecil akan mengganggu semprotan bahan bakar, sehingga sudut semprotan bertambah. Hal ini terjadi akibat penurunan tekanan yang ekstrim pada daerah celah hingga droplet di tepi semprotan akan terhisap ke arah downstream. Distribusi kecepatan pada celah tersebut ditunjukkan pada Gambar 3 dimana intake manifold dengan kecepatan tertinggi terjadi pada bukaan katup $30^{\circ}$. Peristiwa terhisapnya droplet di celah dapat menimbulkan kerugian karena tepat di belakang katup terjadi wake. Wake tersebut menyebabkan sebagian bioetanol mengisi bagian di belakang katup dan tidak dapat tercampur dengan udara, lihat Gambar 4 atas.

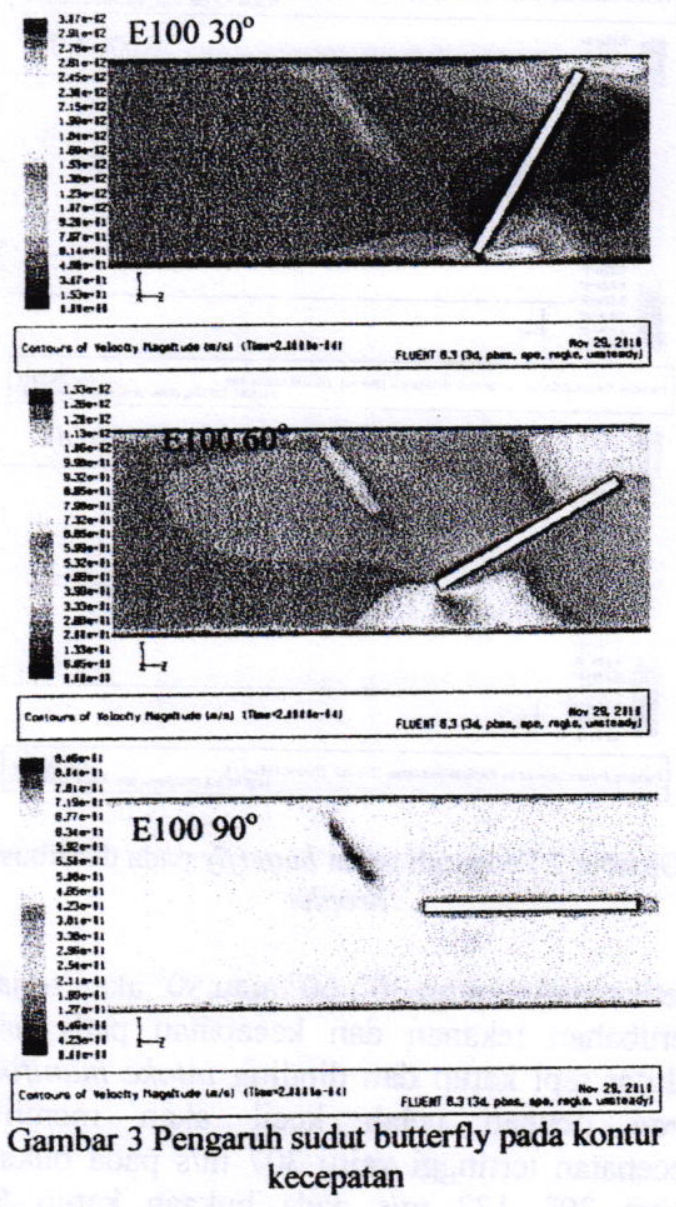

Kerugian lainnya yang ditimbulkan oleh celah yang sempit adalah lapisan bioetanol tipis (fuel film) akan terbentuk di sekitar dinding dan tentu saja proses pencampuran bahan bakar-udara berlangsung kurang sempurna. Kedua hal tersebut, fuel film dan wake dapat mengakibatkan pembakaran di dalam ruang bakar tidak berlangsung sempurna dan dapat meningkatkan polusi.

Beberapa penelitian sebelumnya menjelaskan bahwa bukaan katup paling optimal yang menghasilkan kinerja maksimum pada motor bensin adalah berkisar antara 50 hingga $75 \%$, dalam penelitian ini diwakili oleh Gambar 4 tengah. Pada gambar tersebut area wake yang ditimbulkan relatif lebih kecil, karena perbedaan tekanan di belakang dan di depan katup tidak signifikan. Dengan kata lain, intensitas pencampuran bioetanol dan udara (mixing rate) dalam intake manifold ini akan meningkat.

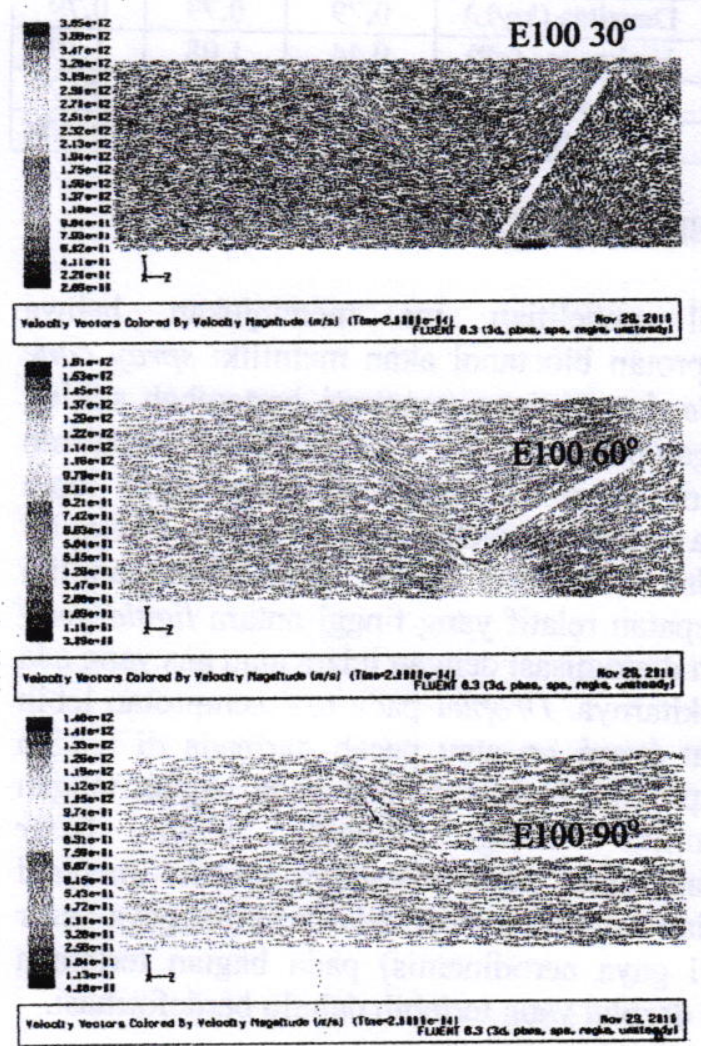

Gambar 4 Pengaruh sudut butterfly pada vektor kecepatan 

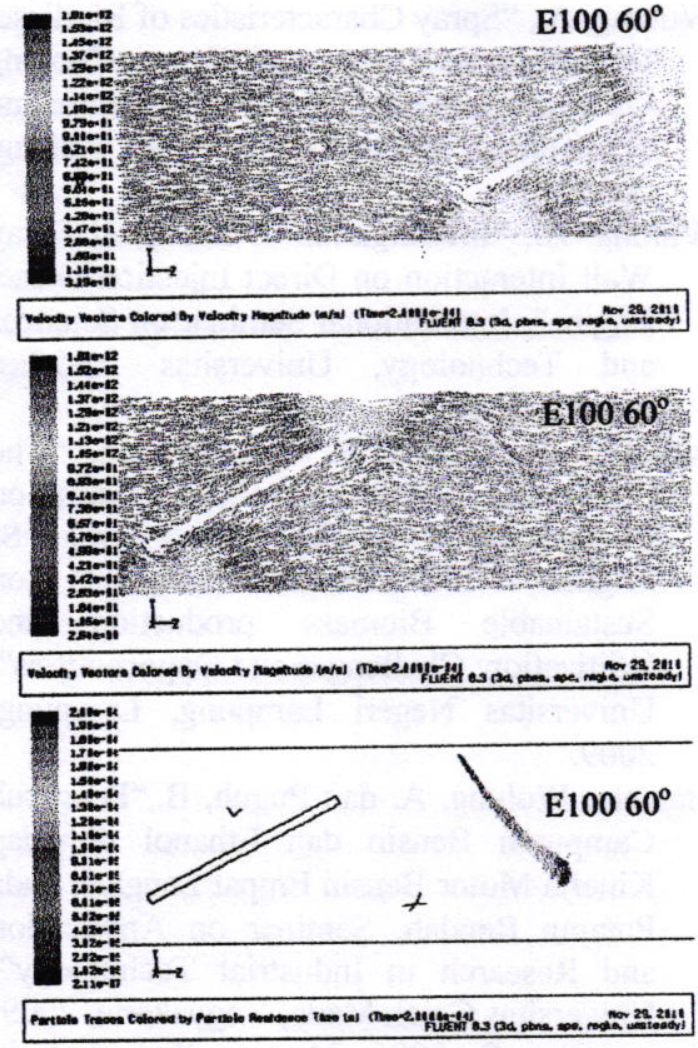

Gambar 5 Pengaruh letak injektor pada vektor kecepatan Sudut butterfly valve 600

Meletakkan injektor setelah butterfly valve diyakini dapat memperbaiki masalah proses pencampuran karena seperti terlihat pada gambar, droplet yang terbentuk tidak menyebar dan membentuk sudut semprotan yang lebih besar. Begitu juga jika diterapkan pada bukaan katup $60^{\circ}$, aliran yang berada di atas katup akan mendorong semprotan hingga menjauhi dinding bawah, Gambar 5.

\section{KESIMPULAN}

Bioethanol memiliki banyak keunggulan dibandingkan bensin. Bahan bakar ini memiliki nilai oktan tinggi 89,7, ramah lingkungan, memiliki atom oksigen yang diharapkan dapat memberikan leaning effect dalam pembakaran. Kecepatan udara yang paling efektif untuk intake manifold berdiameter $22 \mathrm{~mm}$ adalah 60 $\mathrm{m} / \mathrm{s}$ dengan laju massa bioetanol $3 \mathrm{gr} / \mathrm{s}$ karena dapat membentuk campuran ideal 9,1:1. Hasil simulasi numerik ini menunjukkan dalam semprotan bioethanol hanya terjadi collision (pemecahan droplet akibat tumbukan) yang ditunjukkan oleh diameter droplet yang berkisar antara 18,8-134 $\mu \mathrm{m}$. Ketika sudut butterfly valve berubah dan menciptakan celah kecil antara tepi katup dan dinding akan terjadi penurunan tekanan di celah hingga menyebabkan droplet pada tepi semprotan terdorong keluar dari spray cone. Akibatnya spray cone mengalami peningkatan $50 \%$ menjadi $17,44^{\circ}$ ketika sudut katup sudut $30^{\circ}$. Hasil penelitian lainnya adalah viskositas tinggi, menyebabkan bahan bakar memiliki tegangan permukaan yang tinggi sehingga droplet E100, viskositas 1,19 Cs berdiameter lebih besar daripada E85 \& bensin.

Penelitian ini akan diterapkan pada sistem bahan bakar motor bensin, oleh karena itu air fuel ratio dan stoikhiometri lebih diperhatikan agar memperoleh pembakaran yang baik. Parameter lainnya adalah kekasaran dinding intake manifold karena boundary layer dapat menambah ketebalan fuel film.

\section{DAFTAR PUSTAKA}

Al Baghdadi, M. R. S., "A Simulation Model for a Single Cylinder Four-Stroke Spark Ignition Engine Fueled with Alternative Fuels", Turkish J. Eng. Env. Sci. 30, hal. $331-350,2006$.

Al Hasan, M.,"Effect of ethanol-unleaded gasoline blends on engine performance and exhaust emission", Energy Conversion and Management 44, hal. 1547-1561, 2003.

Arias, D. A.,"Numerical and Experimental Study of Air and Fuel Flow in Carburetors for Small Engines, Dissertation, University of Wisconsin-Madison, 2004.

Baumgarten, C.,"Mixture Formation in Internal Combustion Engines", Springer-Verlag Berlin Heidelberg, Germany, 2006.

Ceviz, M.A. dan Yüksel, F.,"Effects of ethanolunleaded gasoline blends on cyclic variability and emissions in an SI engine", Applied Thermal Engineering 25, hal. 917925, 2005.

Ganesan, V.,"Internal Combustion Engines, Third Edition", Tata McGraw-Hill, New Delhi, 2007.

Hira, A. dan Oliveira. L.,'No Subtitute for Oil? 
How Brazil Developed its Ethanol Industry", Energy Policy 37, hal. 24502456, 2009.

Hwang, J.S., HA, J.S. dan No, S. Y.,"Spray Characteristics of DME in Conditions of Common Rail Injection System", International Journal of Automotive Technology, Vol. 4, No.3 hal. 119, 2003.

Kale, S. C. dan Ganesan, V.,"A Study of Steady Flow through a SI Engine Intake System using CFD", 2005.

Makgata, K. W., "Computational Analysis and Optimisation of the inlet system of a highperformance rally engine", University of Pretoria, Thesis, 2005.

Menezes, E. W. dan Calaluña, R., "Optimization of the ETBE (ethyl tert-butyl ether) production process," Fuel Processing Technology (2008), hal. 1148-1152, 2008.

Milton, B. E., Behnia, M. dan Ellerman, D. M., "Fuel Deposition and Re-Atomisation from Fuel/Air Flows Through Engine Inlet Valves", International Journal of Heat and Fluid Flow 22, hal. 350-357, 2001.

Krishna, B. M., Bijucherian, A. dan Mallikarjuna J. M.,"Effect of Intake Manifold Inclination on Intake Valve Flow Characteristics of a Single Cylinder Engine using Particle Image Velocimetry", Proceeding of World Academy of Science, Engineering and Technology Volume 34 Oktober, hal. 861-867, 2008.

Kajitani, S., Oguma, M. and Mori, T.,"DME fuel blends for low-emission, directinjection diesel engines",.SAE Paper No. 2000-01-2004, 2000.

Paasi, J., Kalliohaka, T. dan Glor, M.,"Chargeability of ethanol-petrol biofuels", Journal of Electrostatics 67, hal. 247-250, 2009.

Park, S. W. dan Lee, C. S.,"Macroscopic Structure and Atomization Characteristics of High-Speed Diesel Spray", International Journal of Automotive Technology, Vol. 4, hal. 157, 2003.

Yücesu, H. S., Topgül, T., Çinar C. dan Okur, M.,"Effect of ethanol-gasoline blends on engine performance and exhaust emissions in different compression ratios", Applied Thermal Engineering 26, hal. 2272-2278, 2006.
Wulung, A., "Spray Characteristics of Biodiesel from Jatropa Curcas and Waste Cooking Oil", International Seminar on Sciences and Technology, Universitas Andalas, Padang, 2009.

Wulung, A., "Investigation of Biodiesel Spray Wall Interaction on Direct Injection Diesel Engine", International Seminar on Sciences and Technology, Universitas Andalas, Padang, 2009.

Wulung, A., Puguh, B. dan Slameto, "The Effects of Ethanol-Gasoline Blends on Performance of Modified Four Stroke SI Engine, International Seminar ${ }^{\circ}$ on Sustainable Biomass production and Utlitization: Challenges and Opportunities", Universitas Negeri Lampung, Lampung, 2009.

Slameto, Wulung, A. dan Puguh, B.,"Pengaruh Campuran Bensin dan Ethanol terhadap Kinerja Motor Bensin Empat Langkah pada Putaran Rendah, Seminar on Application and Research in Industrial Technology", Universitas Gajah Mada, Yogyakarta, 2009.

Baumgarten, C. 2006. Mixture Formation in Internal Combustion Engines, SpringerVerlag Berlin Heidelberg, Germany.

Hwang, J.S., HA, J.S. dan No, S. Y. 2003. Spray Characteristics of DME in Conditions of Common Rail Injection System, International Journal of Automotive Technology, Vol. 4, No.3 hal. 119.

Saydut, A., Duz, M. Z., Kaya, C., Kafadar, A. B. dan Hamamci, C. 2008. Transesterified Sesame (Sesamum Indicum L.) Seed Oil as a Biodiesel Fuel, Bioresource Technology Vol. 99, hal. 6656-6660.

Wulung, A. dan Sungkono, D. 2010, Simulasi Numerik Pola Semprotan Bahan Bakar Biodiesel di Ruang bakar Mexican Hat dengan CFD Solver FLUENT 6.3, Prosiding Seminar Nasional Kimia 2010, hal. B 51-58. 